\section{$\underset{\substack{\text { hommes } \\ \text { \& migrations }}}{ }$}

Hommes \& migrations

Revue française de référence sur les dynamiques

migratoires

$1298 \mid 2012$

France - Algérie, le temps du renouveau

\title{
Cinquante ans au compteur de l'histoire
}

\section{Mouloud Akkouche}

\section{(2) OpenEdition \\ Journals}

\section{Édition électronique}

URL : http://journals.openedition.org/hommesmigrations/1582

DOI : 10.4000/hommesmigrations. 1582

ISSN : 2262-3353

\section{Éditeur}

Musée national de l'histoire de l'immigration

\section{Édition imprimée}

Date de publication : 1 juillet 2012

Pagination : 110-111

ISSN : 1142-852X

Référence électronique

Mouloud Akkouche, "Cinquante ans au compteur de l'histoire », Hommes \& migrations [En ligne], 1298 | 2012, mis en ligne le 31 décembre 2014, consulté le 23 avril 2019. URL : http://

journals.openedition.org/hommesmigrations/1582; DOI : 10.4000/hommesmigrations. 1582 


\title{
Cinquante ans au compteur de l'histoire
}

\author{
Par Mouloud Akkouche
}

Que dire sur le cinquantième anniversaire de la libération de l'Algérie ? Né six mois après et peu documenté sur ce sujet, je ne me sentais pas légitime à en parler hors du "café du commerce".Pas directement mon histoire, mais d'autres histoires personnelles à vivre et essayer de comprendre avant de m'intéresser au passé. La dernière fois que j’ai mis les pieds dans ce pays était en 1992 ; mon père et moi chacun dans un avion, lui dans la soute à bagages.

Puis, avec le recul et la réflexion, je crois avoir des choses à dire sur cet événement ou tout du moins les échos ressentis en tant, notamment, que fils de parents nés en Algérie. Peut-être aussi parce que j'ai deux gosses - adultes aujourd'hui - dont une part d'eux se trouve dans les montagnes de Kabylie. À ce propos, le benjamin s'était entiché de l'occitan au collège et défendait cette langue avec une extrême ferveur. Pourquoi un tel engouement? Sans doute lié à ma "non-transmission" du kabyle. Pourquoi ne pas avoir transmis? Je n'en sais fichtre rien. Certains, d'origine maghrébine, m'ont accusé de trop me "franciser", d'autres, "Français de souche", me reprochaient de ne pas défendre ma culture. Même si elles ont une importance, les origines ne sont pas pour tous la clé de voûte d'une existence. Chacun mène comme il peut son chantier de vie et choisit - subit parfois - ses priorités essentielles.

De quelle origine es-tu ? Depuis de nombreuses années, je réponds - naïvement ? par : "J'ai deux patries, l'amour et l'amitié. Le reste, je le laisse aux nationalistes ou à tous les imbéciles heureux qui sont fiers d'être nés quelque part." Mais aujourd'hui, les uns par haine et calcul politique, les autres par excès de compassion ou de culpabilité postcoloniale, envisagent difficilement une partie de la population autrement qu'à travers le prisme des origines. Et ils oublient l'individu, avec ses défauts et qualités. Il y a ceux qui ont du mal à traiter de "sale con" un Arabe ou un Noir de peur d'être taxés de racisme et ceux qui considèrent tout basané comme un délinquant ou un intégriste esclavagiste de femmes. Coincés entre l'enclume d'une forme de "bien-pensance" et le marteau bleu Marine. Dernièrement, j'ai demandé à un serveur s'il était d'origine marocaine. À sa réponse négative assez sèche, j'ai compris qu'il refusait d'être enfermé dans ce genre de considération - surtout par un inconnu. C'est son droit le plus strict. 
Mais doit-on se censurer pour autant sur ces questions? Plus simple de dire : "Vous ne seriez pas marseillais, vous ?"... Quelque temps déjà que nous ne savons plus sur quel pied danser avec les origines.

Pourquoi ne pas essayer de tourner la page de la guerre d'Algérie, laisser les historiens faire leur boulot et nous, chacun sur notre trajectoire, continuer de suivre notre petit bonhomme de chemin? Rester l'ceil rivé sur le rétro n'est pas productif. Cela dit, depuis plusieurs décennies, on ne cesse d'évoquer - souvent pour les incriminer - ces enfants et petits-enfants d'immigrés à la double culture. Beaucoup de ces jeunes et moins jeunes possèdent effectivement cette double culture mais nombre d'entre eux auraient plutôt une double inculture. Ils ne connaissent pas ou très peu la culture et l'histoire de leur pays d'origine, ni celles de la France, et le Français dit "de souche" qui transmettait sa culture aux immigrés pendant les Trente Glorieuses la maîtrise de moins en moins. Un bouillon d'inculture qui, dans les quartiers populaires pour ne pas dire cités HLM, fait le lit des extrémistes de droite et des intégristes musulmans. Même des Maghrébins musulmans, inquiets de l'intégrisme, épousent les thèses du FN. Voilà pourquoi l'enseignement de l'Histoire est d'une grande importance pour éviter qu'elle repasse ses plats tels ce bouillon rance mêlé de soupe populaire aux lardons et chorbas communautaristes. Loin du menu "Liberté,Égalité,Fraternité" sauce laïcité: le meilleur plat de la démocratie.

Ce cinquantième anniversaire pourrait être, sans devenir une hagiographie des dirigeants actuels algériens dont je ne partage pas du tout les idées, un vaste laboratoire de questions sur la guerre d'Algérie et ses conséquences en France. Un vrai débat au sein de toutes les couches de la société. Une façon d'éclairer des zones d'ombre et de détruire ces fantômes haineux qui pourrissent l'inconscient collectif depuis plus d'un demisiècle. Régler définitivement les ardoises de l'Histoire et boire une tournée de thé ou - et - de pinard au Bar de l'Avenir. Une tournée républicaine. À la nôtre !

Mouloud Akkouche, né à Montreuil en 1962, est romancier.

- Cayenne, mon tombeau, Paris, Flammarion, 2002.

- Sur la route de Bauliac, Paris, éd. Baleine, coll. "Série grise”, 1999.

- Les Ardoises de la mémoire, Paris, Gallimard, coll. "Série Noire", 1999.

- Avis déchéance, Paris, Gallimard, coll. "Série Noire", 1998.

- Causse-toujours !, Paris, éd. Baleine, coll. "Le Poulpe" 1997.

- Le Silence des Géants, Paris, L'Archipel, 2009.

- Une marque d'enfer, Paris, Albin Michel, coll. "Le Furet", 1999. 